\title{
Howland Award Presentation to Gilbert B. Forbes
}

\author{
ROBERT A. HOEKELMAN
}

Department of Pediatrics, University of Rochester School of Medicine and Dentistry, Rochester, New York 14642

It is a great honor to introduce Gilbert Forbes as the 1992 John Howland Medalist.

Gilbert Forbes' forefathers emigrated from Scotland to New York City in the late 1600 s. His great-grandfather, the first physician in the family, practiced first in Tarrytown, New York, but moved to Kendall, New York, a farming community 40 miles west of Rochester, in 1835. His grandson, Gilbert's father, was also a physician.

Born in 1915, Gilbert demonstrated his investigative nature early on (Fig. 1). Having learned what was in the basket, he began his explorations of the rest of the world; those explorations continue even today.

After graduating from high school and spending a year at Genesee Wesleyan Seminary, Gilbert matriculated at the University of Rochester, where he obtained his baccalaureate degree in 1936 and his M.D. in 1940. Following an internship at the Strong Memorial Hospital, he took his pediatric residency training at St. Louis Children's Hospital and joined the faculty of Washington University School of Medicine, attaining the rank of Associate Professor in 1950.

The relationship of the Washington University School of Medicine to Los Alamos, the site of the Manhattan project, provided him with a year's experience in 1946 and 1947 as a practicing pediatrician. During this year, he arranged to receive training in radioisotope methodology and techniques, the background for his subsequent interest in radiation biology. Thus, he was able to initiate studies of human metabolism by using radioisotopic methods.

In November 1950, he accepted the first chair of pediatrics at the Southwestern Medical School in Dallas, Texas. Three years later, he followed his long-held dream of returning to Rochester, where he could again devote himself almost exclusively to research and teaching.

In a letter to Bill Bradford, then chairman at Rochester, in which he responded to the invitation to return, Gilbert demonstrated his forthrightness and practicality-traits that have always served him well. He wrote:

In many respects. Dallas has been a lovely place in which to live. We have a number of staunch friends here now, and the city has a certain physical attractiveness. The practitioners have accepted my presence here with good grace, and the faculty is pleasant and easy to work with. Our new Dean is a very capable and personable chap. Nevertheless, Mrs. Forbes and I have reached the conclusion that we would prefer not to remain here permanently, but rather to look forward to making our home in Rochester. It is quite difficult for one not bred and educated in the South to adjust himself to either the Texas climate or its climate of opinion. From the family's standpoint, it would seem desirable to consider making our plans for the not-too-distant-future. The children are fast approaching the age at which lasting friendships are important. Further, since a move will necessitate professional adjustments as well as starting a scientific program in a new setting, we should like to look forward to settling down for good on leaving here.

The general idea of a set-up to my liking involves a combination of teaching and ward responsibilities, time and opportunities for some research, and the privilege of seeing some, but not too many, private patients. Salary should be such as to leave the private-patient aspect in the category of an avocation, not a necessity.

Over the four decades since his return to Rochester in 1953, Gilbert Forbes has become recognized as one of this country's foremost scholars and teachers of pediatrics and human nutrition. In his own way, he has also been a public servant at the national, local, and institutional levels. He has served on several NIH study sections and on committees and advisory boards of the National Research Council, the American Academy of Pediatrics, several foundations, and the University of Rochester Medical School. He served his alma mater as acting cochairman of the Department of Pediatrics from 1974 until 1976. His peers have honored him by electing him president of the Society for Pediatric Research (1960-1961) and vice president of the American Pediatric Society (1975-1976). He has been a frequent guest lecturer and visiting professor in the United States and abroad, and spent the 1970-1971 academic year as a visiting scientist at Oxford University in England.

His scientific contributions earned him a Research Career Award in 1962 from the National Institute of Child Health and Human Development, which has remained in effect for 30 years, the longest on record. He was given the Borden Award for research in pediatric nutrition in 1964. In 1978 he was designated the second Distinguished Alumni Professor at the University of Rochester School of Medicine and Dentistry. In 1979, he was appointed to the Board of Scientific Counsellors of the Children's Nutrition Research Center at Baylor University, a position he held until 1990.

Despite these many outside activities and honors, Gilbert has maintained his central focus as a scholar and an educator. He has been one of the major students of infant and childhood

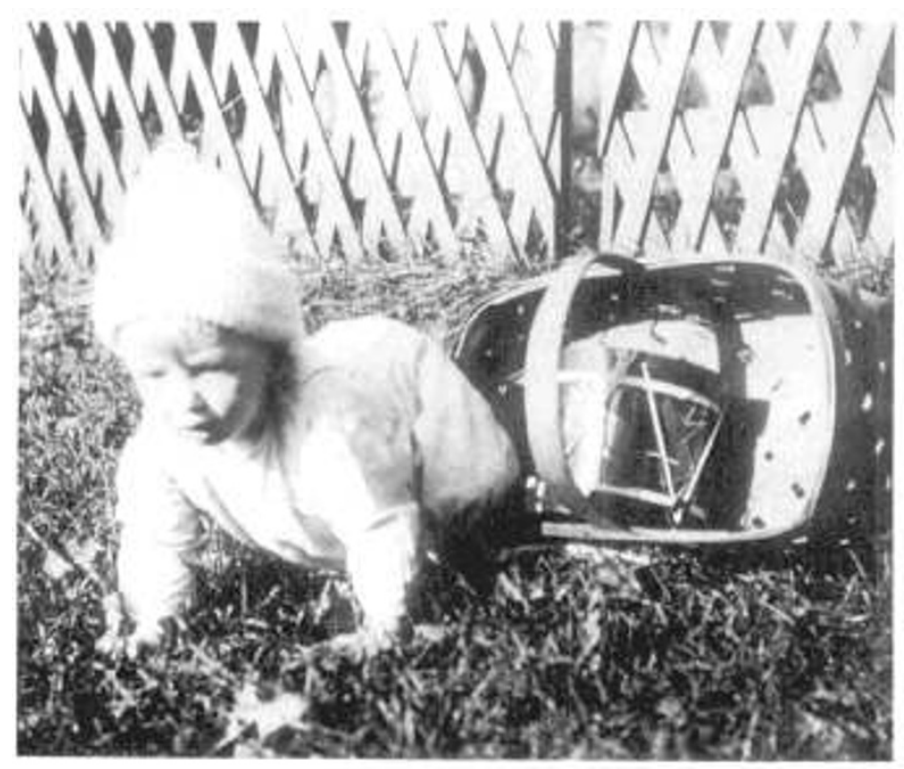

Fig. 1. Gilbert Forbes explores the world around him, circa 1916. 


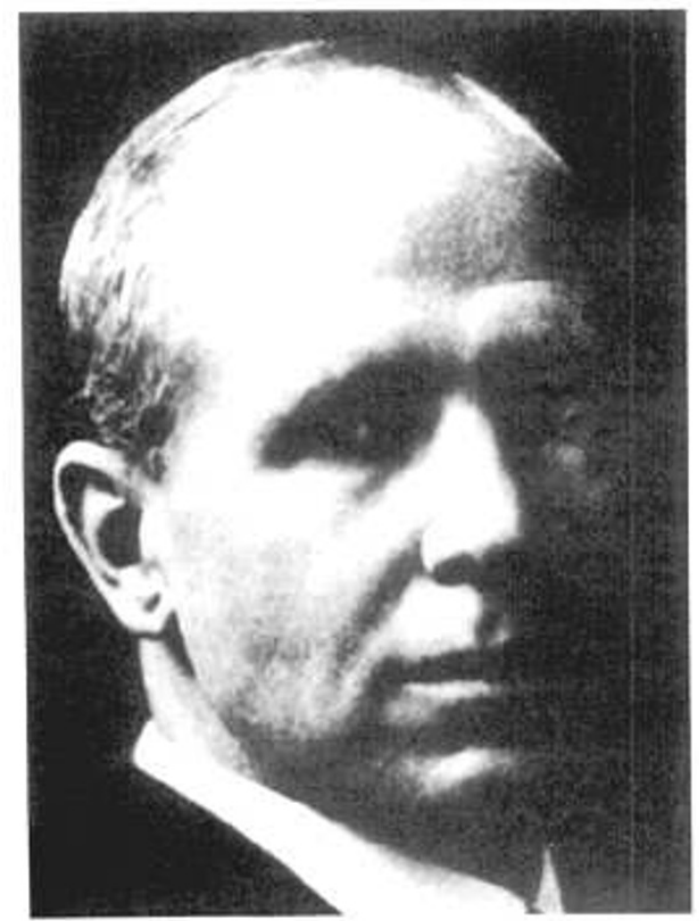

Fig. 2. John Howland, First Chairman, Department of Pediatrics, Johns Hopkins University, 1912-1926.

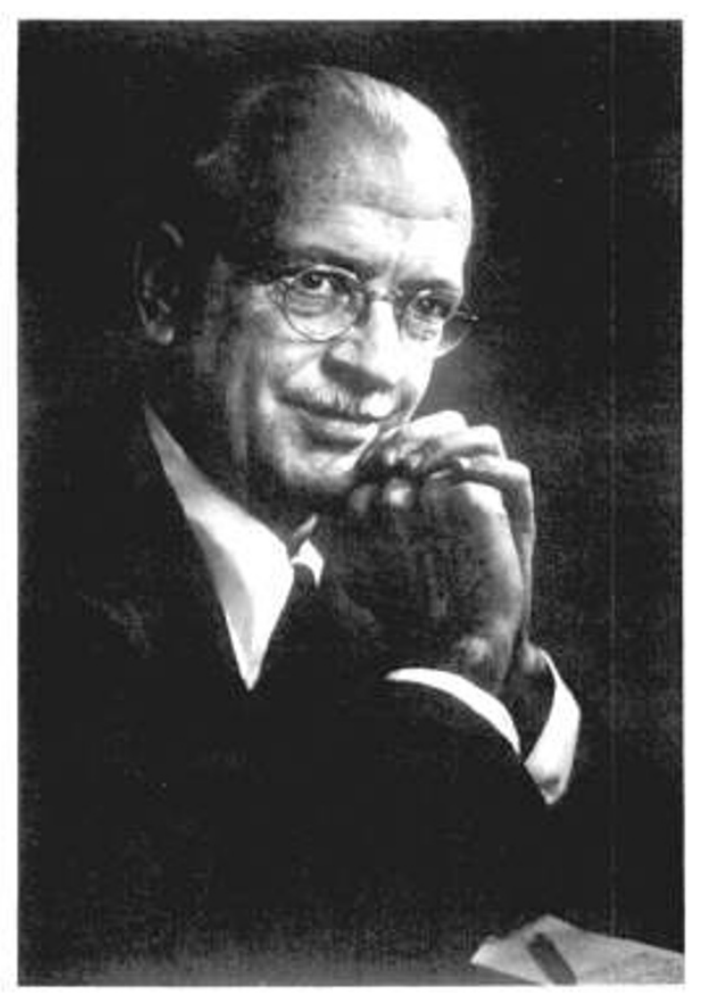

Fig. 3. Samuel W. Clausen, First Chairman. Department of Pediatrics, University of Rochester, 1926-1952.

nutrition and metabolism in this country and the world. He was a pioneer in developing the technique of potassium- 40 counting for estimating lean weight and body fat and has used this technique in the study of nutritional requirements and the effect of nutrition on body composition. He called attention to the hazards of overnutrition in infancy and childhood. He developed a mathematical model for the changes in body composition during fetal life and was able to show that human milk could not

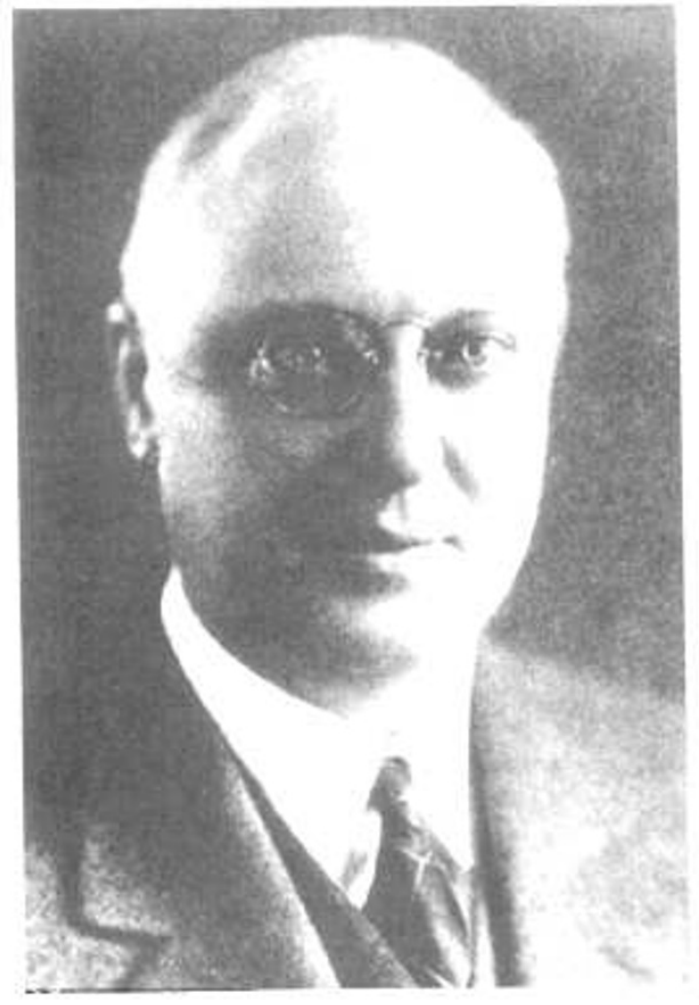

Fig. 4. Williams McKim Marriott. Chairman, Department of Pediatrics, Washington University, 1919-1936.

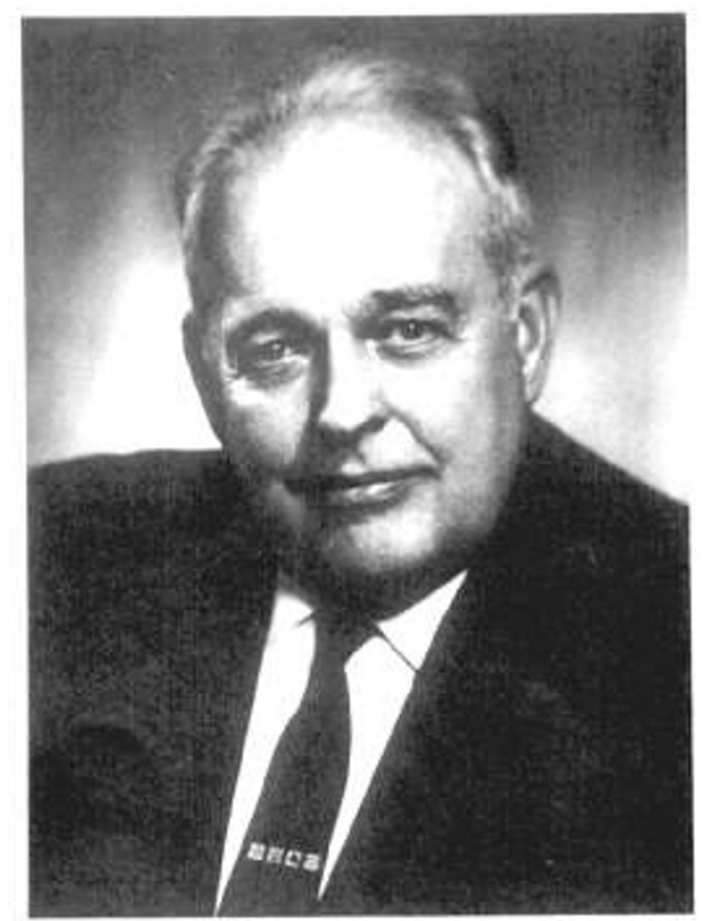

Fig. 5. Alexis Hartmann, Chairman, Department of Pediatrics, Washington University, 1936-1964.

adequately provide for the needs of the rapidly growing prematurely born infant, an unpopular concept at the time of its presentation to the American Pediatric Society in 1978.

In addition, Gilbert served as editor of the American Journal of Diseases of Children from 1974 through 1983 and served two 6-year terms on the Committee of Nutrition of the American Academy of Pediatrics. He also was assistant editor of the Pediatric Nutrition Handbook, published by that organization, and 
Two Branches of the John Howland Academic Family Tree

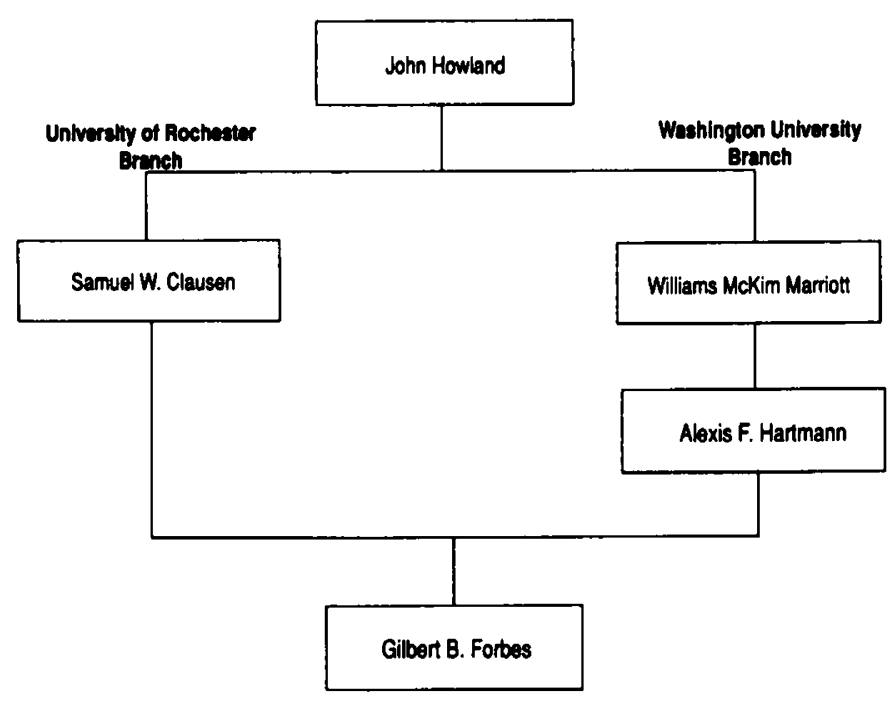

Fig. 6.

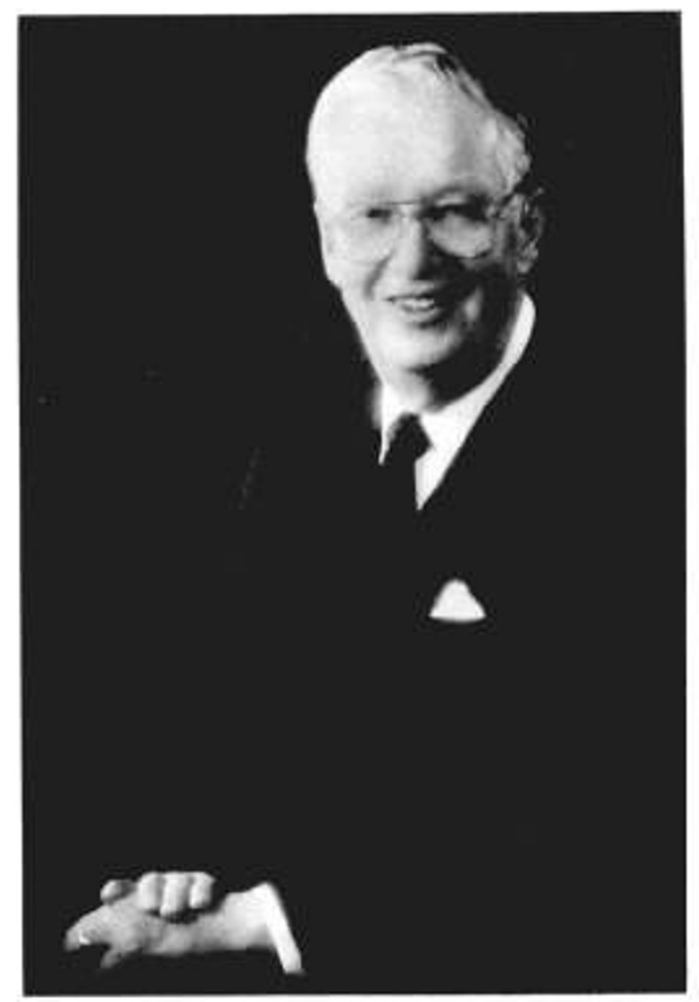

Fig. 7. Gilbert B. Forbes, 1992 Howland Medalist.

was editor of the second edition. He was associate editor of Nutrition Reviews for 10 years and has written a book on human body composition, which was published in 1987 (1). He notes in it that, of all the influences that affect body composition in man, nutrition is one of the most powerful; indeed, it is second only to androgens in this respect. He emphasizes the point that nutritional intake must be controlled when one wishes to evaluate the effect of other influences, such as physical activity or disease, on body composition.

Of significance to his career is that he has never allowed all these activities to interfere with his teaching responsibilities. Throughout his time in academia, he has conducted regular teaching sessions with medical students and house officers, been attending physician on the hospital inpatient units regularly, given lectures to medical students, presented at pediatric grand rounds, and served on Ph.D. committees in physiology and toxicology. He was recognized for these efforts by being elected as an alumnus member of AOA by the student body, and just last year he received a special commendation from the pediatric house staff for his contributions to Morning Report.

A review of Gilbert Forbes' bibliography would stagger most imaginations. Leaving aside some 130 book chapters, editorials, occasional pieces, and letters to the editor for which he is the sole author, his publications include 139 peer-reviewed scientific articles spanning 50 years, for which he is the first author on 48 and the sole author on 45 . The first three of these were published in 1943 and the last four in 1992. He keeps on going and going and going like the Energizer battery-driven toy rabbit drummer.

The rationale for selection of Gilbert Forbes as a recipient of the Howland Medal is clear. The award honors individuals who through their contributions to research and teaching have added to the advancement of pediatrics and to improvement in child health, as did John Howland (Fig. 2). Buford Nichols at the dedication of the Howland Auditorium at the Children's Nutrition Research Center, Baylor College of Medicine, stated that Howland "changed the course of Pediatrics to what we know it now by substituting for bedside observation and conjecture the study of disease through laboratory methods and experiments" (2).

As the first chairman of the first Department of Pediatrics established in the United States (at Johns Hopkins in 1912), Howland stressed the scientific investigation of the causes for and treatment of diseases of infants and children. He, his colleagues at Hopkins, and his pupils were responsible more than any other group of pediatric academicians for the advancement of our knowledge of these maladies. Their work contributed most significantly to the rapid decline in the mortality and morbidity from those diseases, beginning in the 1920 s and continuing thereafter during the balance of the first half of this century. The contributions of most of his pupils to this phenomenon were realized at other medical schools, where they established excellence in pediatric research and teaching. Two of them, Samuel W. Clausen, the first chairman of the Department of Pediatrics at the University of Rochester (1926-1952), and Williams McKim Marriott, chairman of the Department of Pediatrics at Washington University (1919-1936), directly or indirectly influenced Gilbert Forbes' decision to pursue a career in academic pediatrics. Dr. Clausen (Fig. 3) was chairman when Dr. Forbes was a medical student and an intern at Rochester between 1936 and 1941, and Dr. Marriott (Fig. 4) was Alexis Hartmann's mentor. Hartmann, (Fig. 5) who succeeded Marriott as chairman, was Gilbert Forbes' mentor between 1941 and 1950 when he was a resident and young faculty member at Washington University. Figure 6 shows the two branches of the John Howland Academic family tree in which Gilbert Forbes was raisedthe University of Rochester Branch and the Washington University Branch. Thus, Gilbert Forbes (Fig. 7) can be considered both a second- and a third-generation Howland "mentee." As such, his receipt of the Howland Medal emphasizes the longevity of Howland's influence on academic pediatrics.

Finally, Gilbert Forbes' personal and professional qualities place him at the top of any "gentleman and scholar" or "role model" list. He is a warm, generous, loyal, and gentle person, a meticulous investigator, a lucid thinker and communicator, a wise counselor, a distinguished, inspirational leader, and a valued friend. We are all proud of you, Gilbert.

\section{REFERENCES}

1. Forbes GB 1987 Human Body Composition: Growth. Aging. Nutrition, and Activity Springer-Verlag, New York

2. Nichols Jr BL 1991 Dedication of the Howland Auditorium. In: Nichols Jr BL, Belabriga A, Kretchmer N (eds) History of Pediatrics 1850-1950, Nestle Nutrition Workshop Series, Vol 22. Vevey/Raven Press Ltd., New York 